\title{
Anaesthetic Potential of Tobacco (Nicotiana tobaccum) on Clarias gariepinus (Burchell 1822) Fingerlings
}

\author{
Temitope Jegede ${ }^{1}$ \\ ${ }^{1}$ Department of Forestry, Wildlife and Fisheries Management, Ekiti State University, Ado Ekiti, Nigeria \\ Correspondence: Temitope Jegede, Department of Forestry, Wildlife and Fisheries Management, Ekiti State \\ University, Ado Ekiti, Nigeria. E-mail: temitopejegede@yahoo.com
}

\author{
Received: February 8, 2014 Accepted: March 17, 2014 Online Published: April 15, 2014 \\ doi:10.5539/jas.v6n5p86 URL: http://dx.doi.org/10.5539/jas.v6n5p86
}

\begin{abstract}
The efficacy of Nicotiana tobaccum as anaesthetic agents on Clarias gariepinus was investigated in this study. There were dissimilarity $(\mathrm{P}<0.05)$ in the induction and recovery stages at varying concentrations of ethanol extract of Nicotiana tobaccum were identified for Clarias gariepinus. Induction time (in minutes) decreased significantly (T1)109, (T2) 101, (T3) 87, (T4) 79 and (T5) 63, with increasing concentrations of ethanol extract of Nicotiana tobaccum. On the other hand, there were upsurge in the recovery times with a rise concentrations of anaesthetic agent $(\mathrm{P}<0.05)$.

Fish in treatments T3, T4 and T5 started showing signs of uncomfortability on exposure to extracts of Nicotiana tobaccum at higher concentrations, like gasping for air at the air-water inter phase, trying to jump out of the tank, restlessness and eventually settling at the bottom of the tank lifeless (indicating that they have reached anaesthesia).
\end{abstract}

Keywords: anaesthetic, Nicotiana tobaccum, induction time, recovery time

\section{Introduction}

Clariid catfish are widely distributed in Africa (Shelton, 2001), they are Africa's main profitable food fish family (Adebayo \& Fagbenro, 2004) and universally, Nigeria is the largest producer of farm raised Clarias gariepinus (FAO, 2013). The major attribute of the species are hardiness, high prolificacy and simplicity of culture, the existence of arborescent air breathing organ, omnivorous feeding habit, enhance/rapid growth rate and improve feed conversion (Britz \& Pienaar, 1992; Hecht et al., 1996). C. gariepinus is of a great demand because of its striking attributes and enriched taste of its fleshy tissue (Sogbesan \& Ugwumba, 2008).

Fish are usually traumatized when mal-handled during cropping, stocking, sorting, weighing, stripping, and transportation (Gabriel \& Akinrotimi, 2011), consequently resulting to decreased fish performance, increased susceptibility to disease and mortality in extreme cases (Masa et al., 2000).

In order to minimize mortality induced by stress, anaesthetics are commonly dispensed to fish before handling to sedate and immobilize fish (King et al., 2005; L. G. Ross \& B. Ross, 1999). Usually anaesthetics used for fish must have these characteristics: highly solvable in fresh and salt water, rapid induction and recovery time, not poisonous to fish and humans, physiological effects is for a while, rapidly wear off from the body, availability and cost effectiveness (Marking \& Meyer, 1985). Common anaesthetics such as 2-phenoxyethanol, quinaldine, tricaine methane sulphonate (MS-222), eugenol, and benzocaine (Velisek et al., 2011) are highly priced and scarce in resource poor countries. Presently only MS-222 is authorized by law for use on food fish in the United States and in the European Union (Öğretmen \& Gökçek, 2013).

Tobacco (Nicotiana tobacum) a natural biocide is native to tropics and subtropical America but it is now planted profitably globally (Knapp, 2004). Tobacco contains phytochemicals like, Glucosides (tabacinine, tabacine), Nicotianine, Nicotine, , Anabasine, 2-Methylquinone, Acrolein, Anthalin, 2-Napthylamine, Acrolein,, Anatalline, Anethole, Anatabine, Cembrene, Choline, Pyrene, Acrolein, Nicotelline and 2,3,6-Trimethyl-1,4-naphthoquinone in addition they are generally known as being narcotic/anaesthetic (Agbon et al., 2002).

Consequently in the quest for safer, more effective, readily available, affordable, eco-friendly and easily adaptable anaesthetic which is comparable to conventional chemical anaesthetics, tobacco, a popular narcotic, is hoped to be this suitable alternative. 
Therefore the aim of this study is to determine the efficacy and optimum concentration of ethanol extract of tobacco as anaesthetic on Clarias gariepinus fingerlings.

\section{Materials and Methods}

\subsection{Experimental Fish}

Two hundred and fifty $C$. gariepinus fingerlings of multi -sex [of matching brood stock] superficially perceived to be healthy $(5.63 \pm 0.42 \mathrm{~g})$ were acquired from Afe Babalola University Fish Farm, Ado Ekiti, Ekiti State. They were taken live to the newly built Aquaculture and Fisheries Management laboratory of the Faculty of Agricultural Sciences, Ekiti State University, Ado Ekiti, in a 50 L capacity plastic container, half filled with pond water between 1700-1730h. They were later kept in rectangular plastic tanks $60 \mathrm{~L}$ capacity where they were set to adjust to laboratory conditions for 7 days.

\subsection{Experimental Plant}

Nicotiana tobaccum leaves were collected along Iworoko- Ifaki town settlements, Ekiti State, Nigeria, this was followed by drying under shade at ambient temperature and pulverized into fine particle size $(<250 \mu \mathrm{m})$; and stored in a clean, dry, air-tight plastic vessel.

\subsection{Ethanol Extract}

Pulverized Nicotiana tobaccum (500 g) was packaged into soxhlet extractor, using ethanol as solvent for the extraction, after which distillation of the solvent takes place. One hundred (100) g ml of the ethanol extract Nicotiana tobaccum was obtained using soxhlet method (AOAC, 1999).

\subsection{Induction and Recovery Stages of Anaesthesia}

The efficacy of Nicotiana tobacum on C. gariepinus fingerlings was assessed by testing varying concentrations of ethanol extracts of Nicotiana tobacum. The concentrations at which C. gariepinus reached anaesthesia were determined by first conducting a range finding test.

Shortly before the initiation of the research, the fish were allowed to go hungry for 2 days to minimize waste in the test media and to prevent organic decay and depletion of oxygen. This research was conducted under standard static bioassay specification. Dissolved oxygen, Temperature, $\mathrm{pH}$ and conductivity level were measured using standard methods and readings were taken at $24 \mathrm{~h}$ interval for $96 \mathrm{~h}$.

Ten Clarias gariepinus fingerlings ( $5.63 \pm 0.42 \mathrm{~g}$ ) were kept in each rectangular tank $(75 \times 40 \times 40) \mathrm{cm}, 2 / 3$ filled with clean and aerated water with three replicates per treatment.

The treatments are: (T1)1.25, (T2)2.50, (T3)3.75, (T4)5.00 and (T5)6.25 g/Litre of water. The induction and recovery time of each concentration was measured and monitored using chronological watch.

Clarias gariepinus fingerlings were introduced into each treatment and the behaviour(s) of the fingerlings monitored and recorded. Temperature, Dissolved oxygen and $\mathrm{pH}$ were measured and recorded using standard methods and readings were taken at interval of $24 \mathrm{~h}$ for $96 \mathrm{~h}$.

The recovery process was actually done in a recovery tanks $(75 \times 40 \times 40) \mathrm{cm}, 2 / 3$ filled with clean and aerated water having no Nicotiana tobaccum extract. The recovery time were monitored using chronometer.

\subsection{Statistical Analysis}

Data obtained from this research were made to undergo one-way Analysis of Variance (ANOVA) test using the Statistical Package for Social Science (SPSS) Version 11. Fisher's pairwise comparison was used in comparing variations between anaesthetic doses, recovery and induction times.

\section{Results}

There were significant differences $(\mathrm{P}<0.05)$ in the induction and recovery stages of Clarias gariepinus subjected to different concentrations of ethanol extract Nicotiana tobaccum. Induction time (in minutes) decreased significantly (T1)109, (T2) 101, (T3) 87, (T4) 79 and (T5) 63, with increasing concentrations of ethanol extract of Nicotiana tobaccum. On the other hand, increase in the concentration of anaesthetic agent $(\mathrm{P}<0.05)$ (Table 1) (Fig.1) leads to an upsurge in recovery times.

The induction time was recorded immediately the fish was noticed to be lossing of equilibrium and the fish began to swim vertically. Recovery time was recorded when equilibrium was regained.

Fish in treatments T3, T4 and T5 started showing signs of uncomfortability few minutes after exposure to extract of Nicotiana tobaccum at higher concentrations, like gasping for air at the air-water inter phase, restlessness and settling at the bottom of the tanks lifeless(indicating that they have reached anaesthesia). 
Also, there were no mortality recorded in Treatments 1 and 2, however mortality were recorded in Treatments 3, 4 and 5 respectively $(20,45$ and $60 \%)$. Mortality increases with increase in concentrations of the extract of Nicotiana tobaccum (Table 1).

Table 1. Induction, Recovery and Mortality of Clarias gariepinus fingerlings exposed to ethanol extract of Nicotiana tobaccum leaf dust as anaesthetic agent

\begin{tabular}{llll}
\hline Concentration (g/10L) & Induction Time (mins.) & Recovery Time (mins.) & Mortality (\%) \\
\hline 0 (Control) & & & \\
1.25 & 109 & 44 & - \\
2.50 & 106 & $53-65$ & - \\
3.75 & 87 & 70 & 20 \\
5.00 & 79 & 85 & 45 \\
6.25 & 63 & Never recovered & 60 \\
\hline
\end{tabular}

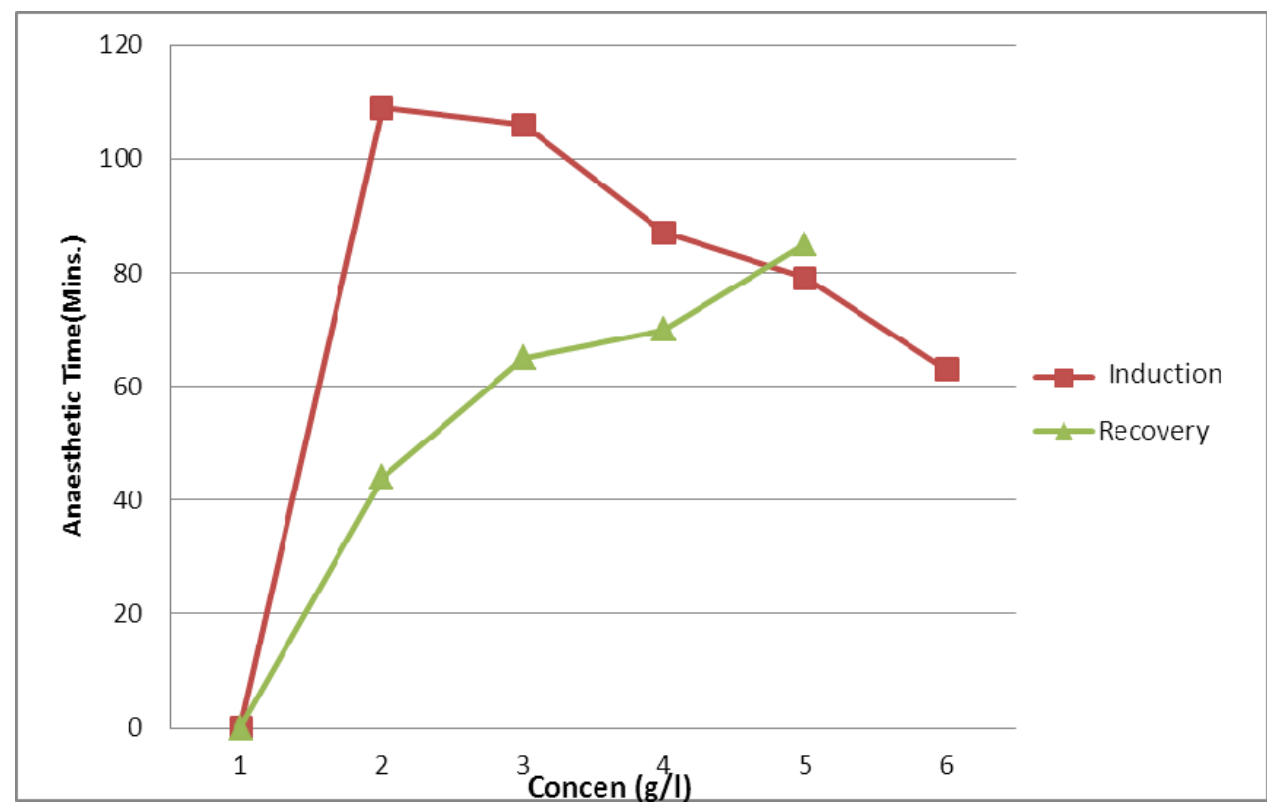

Figure 1. Induction and recovery times of Clarias gariepinus fingerlings anaesthetized with ethanol extract of Nicotianna tobaccum

\section{Discussion}

In this present study, induction time decrease significantly $(\mathrm{p}<0.05)$ with increase in concentrations of ethanol extract Nicotiana tobaccum. This result corroborates a previous research by Agokei and Adebisi (2010) where aqueous extract of tobacco (Nicotiana tobaccum) was tested on Oreochromis niloticus fingerlings. It was reported that as the concentrations of aqueous extract of tobacco increases anaesthetic time also decreases. Also a similar study by Öğretmen and Gökçek (2013) showed that as the concentrations of clove oil, 2-phenoxyethanol and eugenol (anaesthetic agents) increases, the induction and recovery time for Clarias gariepinus also decreases. Even though the time to reach induction and recovery in this study is on the high side, higher than that reported Agokei and Adebisi (2010) and by Öğretmen and Gökçek (2013) this study corroborate the study by Akinbulumo (2005) on the anestethic effect of ethanolic extract and aqueous extract of dried root powder of Derris elliptica on Oreochromis niloticus, The induction and recovery time reported for both aqueous and ethanolic extracts of Derris elliptica on Oreochromis niloticus was 48min and 45-60min as well as 30mins and 50 - 65 mins respectively at $1.5 \mathrm{~g} / 10 \mathrm{~L}$ concentration.

Also in this study, fish in treatments T3, T4 and T5 started showing signs of un-comfortability immediately after exposure to extracts of Nicotiana tobaccum at higher concentrations, like gasping for air at the air-water inter 
phase, restlessness and eventually settling at the bottom of the tank lifeless. This corroborate a akin research by Jegede and Olanrewaju (2012) where Clarias gariepinus exposed to Nicotiana tobaccum leaf dust toxicity showed abnormal behaviours like erratic swimming, hyperventilation, vertical/spiral swimming positions, weakened swimming motions and settling at the bottom.

\section{Conclusion}

The ethanol extract of Nicotianna tobaccum at $2.5 \mathrm{~g} / 10 \mathrm{~L}$ may be used as anaesthetic agent on Clarias gariepinus fingerlings up to 53-65 minutes. Consequently, tobacco (which is readily available, cheaper and even eco-friendly) plant anaesthetic could be a better alternative to costly synthetic anaesthetics.

\section{References}

Adebayo, O. T., \& Fagbenro, O. A. (2004). Induced ovulation and spawning of pond raised African giant catfish, Heterobranchus bidorsalis by exogenous hormones. Aquaculture, 242, 229-236. http://dx.doi.org/10.1016/j.aquaculture.2004.07.019

Agbon, A. O., Omoniyi, I. T., \& Teko, A. A. (2002). Acute toxicity of tobacco (Nicotiana tobaccum) leaf dust on Oreochromis niloticus and haematological change resulting from sub-lethal exposure. J. Aquatic Sci., 17(1), 5-8. http://dx.doi.org/10.4314/jas.v17i1.19901

Agokei, O. A., \& Adebisi, A. A. (2010). Tobacco as an anesthetic for fish handling procedures. Journal of Medicinal Plants Research, 4(14), 1396-1399.

Akinbulumo, M. O. (2005). Derris elliptica roots as anaesthetic agent for Nile tilapia. Oreochromis niloticus. Applied Tropical Agriculture, 10, 24-29.

Association of Official Analytical Chemists (AOAC). (1999). Official Methods of Analysis (16 ed., pp. 600-792). Association of Official Analytical chemists. Arlington, V.A, U.S.A.

Britz, P. J., \& Pienaar, A. G. (1992). Laboratory experiments on the effects of light and cover on the behaviour an growth of African Catfish, Clarias gariepinus. Journal of Zoology, 227, 43-62. http://dx.doi.org/10.1111/j.1469-7998.1992.tb04343.x

FAO. (2013). Fisheries and Aquaculture-Cultured Aquatic Species Information Programme. State of the world aquaculture. FAO FishStat J. Universal Software for fishery statistic time series.

Gabriel, U. U., \& Akinrotimi, O. A. (2011). Management of stress in fish for sustainable aquaculture development. Researcher, 3(4), 28-38.

Hecht, J., Oellermann, L., \& Verheust, L. (1996). Perpectives on clariid catfish culture in Africa. Aquat. Living Resour, 9, 197-206 (Hors Serie). http://dx.doi.org/10.1051/alr:1996054

Jegede, T., \& Olanrewaju, B. (2012). Piscicidal effect of tobacco (Nicotiana tobaccum) leaf dust on African giant catfish (Heterobranchus bidorsalis) fingerlings. Agriculture and Biology Journal of North America, 3(11), 435-438. http://dx.doi.org/10.5251/abjna.2012.3.11.435.438

King, W. V., Hooper, B., Hillsgrove, S., Benton, C., \& Berlinsky, D. (2005). The use of clove oil metomidate, tricaine and phenoxyethanol for inducing anaesthetics on their effect on the cortisol stress response in black sea bass Centropristiss striata) Aquaculture Research, 36, 1442-1449. http://dx.doi.org/10.1111/j.1365-2109.2005.01365.x

Knapp E. (2004). Nomenclatural changes and a new sectional classification in Nicotiana (Solanaceae) Taxon, 53(1), 73-82. http://dx.doi.org/10.2307/4135490

Marking, L. L., \& Meyer, E. P. (1985). Are better anesthetics needed in fisheries? Fisheries, $10,2-5$. http://dx.doi.org/10.1577/1548-8446(1985)010<0002:ABANIF >2.0.CO;2

Mese, M. G., Maule, A. G., \& Schreck, C. B. (2000). Interaction of infection with Reinbacterium salmoninarum and physical stress in juvenile Chinook salmon: physiological responses, disease progression and mortality. Tras. Am. Fish. Soc., 129, 158-173. http://dx.doi.org/10.1577/1548-8659(2000)129<0158:IOIWRS> 2.0.CO;2

Öğretmen, F., \& Gökçek, K. (2013). Comparative efficacy of three anesthetic agents on juvenile African Catfish, Clarias gariepinus (Burchell, 1822). Turkish Journal of Fisheries and Aquatic Sciences, 13, 51-56. http://dx.doi.org/10.4194/1303-2712-v13_1_07

Ross, L. G., \& Ross, B. (1999). Anesthetics and sedative techniques for aquatic animals. Oxford: Blackwell Sci. 
Sogbesan, A. O., \& Ugwumba, A. A. A. (2008). Nutritional Evaluation of Termite (Macrotermes subhyalinus) Meal as animal protein Supplements in the Diets of Heterobranchus longifilis (Valenciennes, 1840) Fingerlings. Turk. J. Fish. Aquat. Sci., 8, 149-157.

Velisek, J., Stara, A., Li, Z. H., Silovska, S., \& Turek, J. (2011). Comparison of effects of four anaesthetics on blood chemical profiles and oxidative stress biomarkers in rainbow trout. Aquaculture, 310, 369-375. http://dx.doi.org/10.1016/j.aquaculture.2010.11.010

Woody, C. A., Nelson, J., \& Ramtod, R. (2002). Clove oil as an anaesthetic for adult sockeye salmon: field trials. Journal of fish Biology, 60, 340-347. http://dx.doi.org/10.1111/j.1095-8649.2002.tb00284.x

\section{Copyrights}

Copyright for this article is retained by the author(s), with first publication rights granted to the journal.

This is an open-access article distributed under the terms and conditions of the Creative Commons Attribution license (http://creativecommons.org/licenses/by/3.0/). 